\title{
Influence of Inverter Controller Parameters on the Small-signal Stability of LCC-HVDC System Based on a Practical Project
}

\author{
Huan $\mathrm{LI}^{1 *}$ and Kang QIN ${ }^{1}$ \\ ${ }^{1}$ Electrical Power Research Institute, CSG, State Key Laboratory of HVDC. Guangzhou, China
}

\begin{abstract}
Unreasonable control parameters of the Line Commutated Converter based High Voltage Direct Current (LCC-HVDC) system may induce small-signal instability. This paper studies the impact of inverter controller parameters on steady response of the LCC-HVDC system under weak AC grid condition. Firstly, according to a practical project, the small-signal model of LCC-HVDC system is established based on the switching function. Then, the eigen-analysis method is adopted to study the impact of the controller parameters on the inverter side on the oscillation mode and damping characteristics of the LCC system, and the correctness of results is verified by PSCAD/EMTDC simulation. The conclusion shows that reasonable controller parameters can improve the stability margin of the system.
\end{abstract}

\section{Introduction}

Line Commutated Converter based High Voltage Direct Current (LCC-HVDC) system has the advantages of lower loss and large capacity power transmission, which plays an important role in realizing the optimal configuration of cross-regional power resources [1]. However, when the inverter station is connected to a weak grid, some inherent problems of LCC-HVDC system may arise such as commutation failure and voltage instability issues. The occurrence of these problems is largely affected by control parameters of the system [2],[3].

References [4]-[6] analyze the effects of the phaselocked loop (PLL) parameters and AC system parameters on the steady performance of LCC-HVDC system. The results show that the stability of LCC rectifier station is enhanced with the increase of PLL parameters, while the conclusion for the inverter station is just the opposite. In [7]-[8], the impact of PLL and constant extinction angle control parameters on the stability of the system is investigated based on a linearized dynamic model of the LCC inverter station. However, the rectifier station and DC line are equivalent to an ideal current source, so the influence of short circuit ratio (SCR) on the rectifier side on the stability of the system is ignored. In [9]-[10], a comprehensive comparison of the impact of constant voltage control and constant extinction angle control on small-signal stability of HVDC is conducted, and the stable region of control parameters which can maintain the stable operation of system is calculated. In the aspect of the small-signal analysis, the existing literatures are based on the CIGRE benchmark model [11] to study the influence of control parameters. However, the structure of $\mathrm{AC} / \mathrm{DC}$ filter banks applied in the practical engineering is more complex, so there is a need to take a practical LCC-
HVDC system as the studied object and analyze how to choose controller parameters reasonably to enhance the small-signal stability of the system.

The rest of this paper is organized as follows. In Section 2, a dynamic phasor model of LCC-HVDC system on basis of a practical project is established. The correctness of the small-signal model is verified by PSCAD/EMTDC simulation in Section 3. Section 4 presents the impact of controller parameters at the inverter station on small-signal stability of the system under weak AC grid condition by adopting eigenvalue analysis. Finally, Section 5 concludes the paper.

\section{Small-signal dynamic model}

\subsection{Study system}

The study system is a monopole double-ended 12-pulse LCC-HVDC system which is based on a practical engineering. Constant current control strategy is adopted at the rectifier station while constant voltage control strategy is used at the inverter station. The single-line diagram of the system is shown in figure 1. The subscript $r$ and $i$ represent the variables on the rectifier side and the inverter side, respectively. $V_{\mathrm{s}}$ denotes the AC system voltage. $U_{\mathrm{pcc}}$ represents the line voltage at the point of common coupling (PCC). $i_{\mathrm{s}}$ and $i_{\mathrm{c}}$ are the current of AC system and the converter transformer, respectively. The $\mathrm{DC}$ transmission line is equivalent to the T-type circuit. $R_{\mathrm{dc}}$ and $L_{\mathrm{dc}}$ represent resistance and inductance of DC line. $L_{\mathrm{ec}}$ is the sum of the equivalent inductance of the converter on the DC side and the inductance of the smoothing reactor. Additionally, $L_{\mathrm{T}}$ is the equivalent inductance of the transformer. $R_{\mathrm{S}}$ and $L_{\mathrm{S}}$ denote resistance and inductance of AC system. $Z_{\mathrm{fac}}$ and $Z_{\mathrm{fdc}}$ represent AC filter banks and DC

*Corresponding author's e-mail: lihuan3@csg.cn 
filter banks, the specific configurations of which are

shown in figure 2 and figure 3 , respectively.

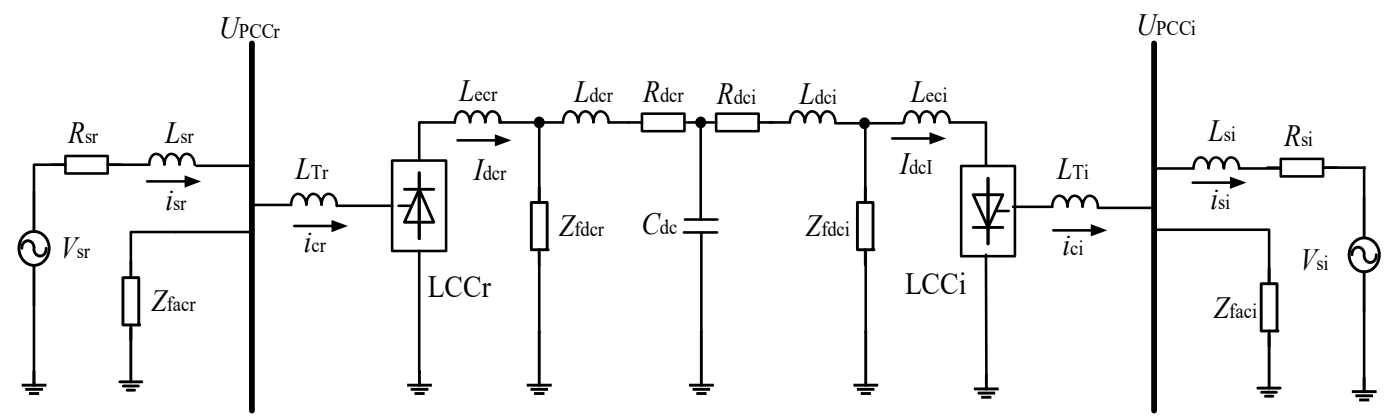

Figure 1. Single-line diagram of the LCC-HVDC system.

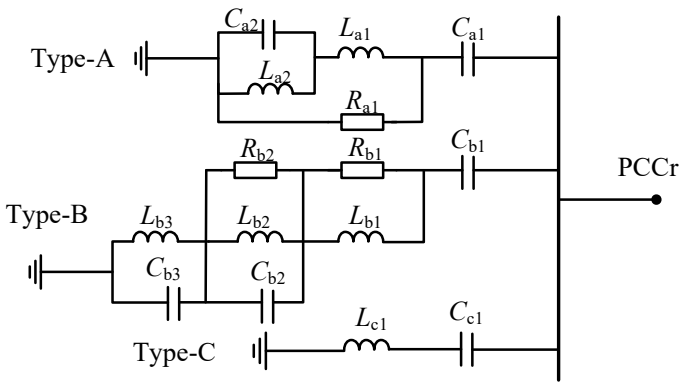

(a)

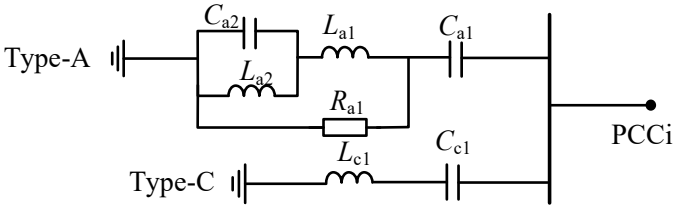

(b)

Figure 2. The configuration of the AC filter banks: (a) the rectifier side; (b) the inverter side.

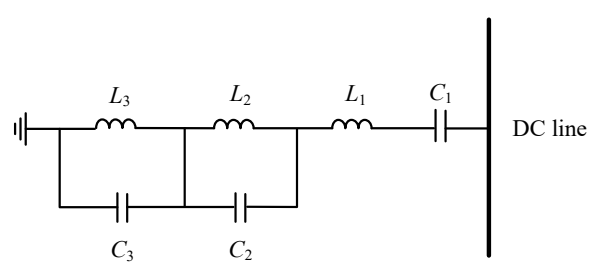

Figure 3. The configuration of the DC filter banks.

\subsection{State space model}

2.2.1 Converter station model. In this paper, the switching function method is used to describe the input/output relationship of converter station [9]. Take the rectifier station as an example. The AC side current of converter can be derived as

$$
\left\{\begin{array}{l}
i_{\mathrm{cdr}}=2 I_{\mathrm{dcr}} A_{\mathrm{i}} \cos \left(\varphi_{\mathrm{r}}+\theta_{\mathrm{PLLr}}-\omega_{0} t-\theta_{\mathrm{acr} 0}\right) \\
i_{\mathrm{cqr}}=-2 I_{\mathrm{dcr}} A_{\mathrm{i}} \sin \left(\varphi_{\mathrm{r}}+\theta_{\mathrm{PLLr}}-\omega_{0} t-\theta_{\mathrm{acr} 0}\right)
\end{array}\right.
$$

where

$$
A_{\mathrm{i}}=\frac{2 \sqrt{3}}{\pi} \frac{\sin \frac{\mu_{\mathrm{r}}}{2}}{\frac{\mu_{\mathrm{r}}}{2}}
$$

In (1), $i_{\text {cdr }}$ and $i_{\text {cqr }}$ are d-axis and q-axis component of the AC side current of converter. $I_{\mathrm{dcr}}$ is DC side current and $\varphi_{\mathrm{r}}$ is power factor angle. $\theta_{\mathrm{PLLr}}$ is the output angle from PLL while $\theta_{\text {acro }}$ is the initial phase of the voltage of PCC. $\omega_{0}$ is the fundamental angular frequency. In (2), $\mu_{\mathrm{r}}$ is commutation overlap angle.

2.2.2 The control system model. The block diagrams of the constant current controller and the constant voltage controller are shown in figure 4.

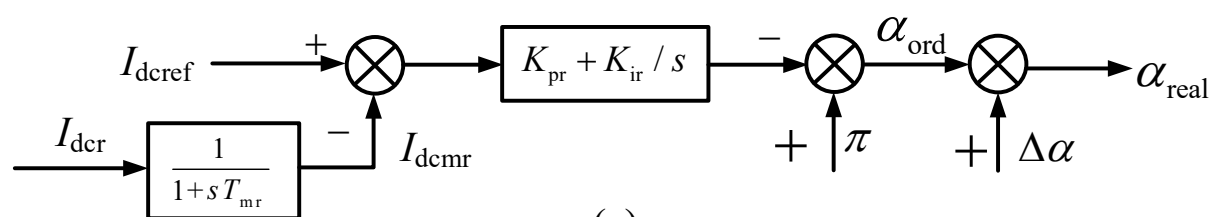

(a) 


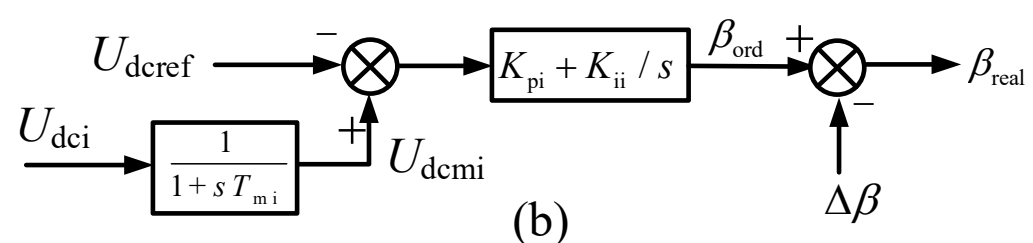

Figure 4. The block diagrams: (a) the constant current controller on the rectifier side; (b) the constant voltage controller on the inverter side.

The corresponding state space equation can be link. expressed as

$$
\left\{\begin{array}{l}
\frac{\mathrm{d} x_{1 \mathrm{r}}}{\mathrm{d} t}=I_{\mathrm{dcref}}-I_{\mathrm{dcmr}} \\
\pi-\alpha_{\mathrm{ord}}=K_{\mathrm{pr}} \frac{\mathrm{d} x_{1 \mathrm{r}}}{\mathrm{d} t}+K_{\mathrm{ir}} x_{1 \mathrm{r}}
\end{array}\right.
$$

Where $x_{1 \mathrm{r}}$ is the state variable of constant current controller and $I_{\text {dcref }}$ is the reference DC-current. $K_{\text {pr }}$ and $K_{\text {ir }}$ are the proportion and the integral gain of the controller. The measured current $I_{\mathrm{dcmr}}$ is obtained by the actual DC current of rectifier through the first-order inertia link, whose state space equation can be expressed as

$$
T_{\mathrm{mr}} \frac{\mathrm{d} I_{\mathrm{dcmr}}}{\mathrm{d} t}=I_{\mathrm{dcr}}-I_{\mathrm{dcmr}}
$$

Where $T_{\mathrm{mr}}$ is the time constant of the first-order inertia

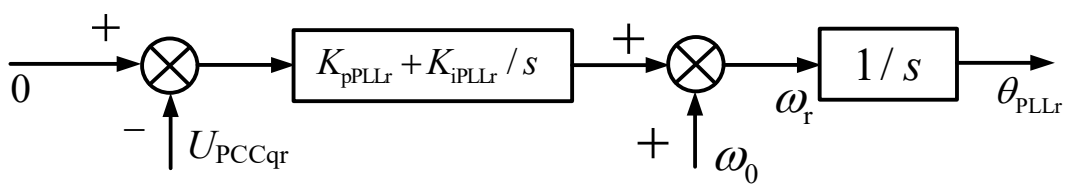

Figure 5. PLL model at the rectifier station.

The corresponding state space equation is shown in (6)

$$
\left\{\begin{array}{l}
\frac{\mathrm{d} \theta_{\mathrm{PLLr}}}{\mathrm{d} t}=\omega_{\mathrm{r}} \\
\frac{\mathrm{d} \omega_{\mathrm{r}}}{\mathrm{d} t}=-K_{\mathrm{pPLLr}} \frac{\mathrm{d} U_{\mathrm{PCC} \mathrm{r}}}{\mathrm{d} t}-K_{\mathrm{iPLLr}} U_{\mathrm{PCC} \mathrm{r}}
\end{array}\right.
$$

Where $\omega_{\mathrm{r}}$ and $\theta_{\mathrm{PLLr}}$ are the angular frequency and angle from the PLL. $U_{\text {pccqr }}$ is the q-axis component of AC voltage of PCC $\left(U_{\mathrm{pccr}}\right)$. $K_{\mathrm{pPLLr}}$ and $K_{\mathrm{iPLLr}}$ are the proportion and the integral gain of the PLL. The state space equation of PLL model at the inverter station is similar to formula (6).

Additionally, the modeling method of AC system, DC transmission line, DC filter banks and AC filter banks has been described in detail in [7].

\subsection{Small-signal dynamic model of LCC-HVDC system}

By the linearization of the above state space model, the
When the output angle of PLL ( $\left.\theta_{\text {PLLr }}\right)$ is not equal to the AC voltage phase of $\operatorname{PCC}\left(\theta_{\mathrm{r}}\right)$, there is a deviation $\Delta \alpha$ between the actual delay trigger angle $\alpha_{\text {real }}$ and the output reference angle $\alpha_{\text {ord }}$. The expression is as follows:

$\alpha_{\text {real }}=\alpha_{\text {ord }}+\left(\theta_{\mathrm{r}}-\theta_{\mathrm{PLLr}}\right)=\alpha_{\text {ord }}+\left(\omega_{0} t+\theta_{\text {acr } 0}-\theta_{\text {PLLr }}\right)=\alpha_{\text {ord }}+\Delta \alpha$

Similarly, the state variables of the constant voltage controller are $x_{1 \mathrm{i}}$ and $U_{\mathrm{dcmi}}$, and the corresponding state space equation can be derived in the same form as (3)-(5), which is not described here.

2.2.3 PLL model. The control principle of the PLL at the rectifier station is equivalent to the structure block diagram shown in figure 5 .

Table 1. The main parameters of LCC-HVDC.

\begin{tabular}{llll}
\hline The Group & Parameter Description & \multicolumn{2}{c}{ Value } \\
\cline { 3 - 4 } & & Rectifier & Inverter \\
\hline \multirow{2}{*}{ The rated value } & DC current $(\mathrm{kA})$ & 3 & \\
& DC voltage $(\mathrm{kV})$ & 500 & 525 \\
& AC voltage $(\mathrm{kV})$ & 525 & 5.0 \\
\hline The AC system & Short-circuit ratio & 5.0 & \\
\hline
\end{tabular}




\begin{tabular}{llll}
\hline & Impedance angle & $86.185^{\circ}$ & $85.23^{\circ}$ \\
& PCC voltage (p.u.) & 1.0 & 1.0 \\
\hline \multirow{2}{*}{ The transformer } & Leakage reactor (p.u.) & 0.16 & 0.152 \\
& Capacity (MVA) & 889.5 & 833.4 \\
& Ratio of voltage & $525 / 209.7$ & $525 / 196.5$ \\
\hline The PLL & Proportion gain & 10 & 10 \\
& Integral gain & 50 & 50 \\
\hline \multirow{2}{*}{ The control } & Proportion gain & 0.2 & 0.5 \\
& Integral gain & 100 & 50 \\
& Time constant (s) & 0.0012 & 0.02 \\
\hline \multirow{2}{*}{ The DC line } & Inductor(H) & 0.1979 & 0.1979 \\
& Resistor( $\Omega$ ) & 5.2 & 5.2 \\
& Capacitor(uF) & 39 & \\
& Smoothing inductor(H) & 0.3 & 0.3 \\
\hline
\end{tabular}

Table 2. The parameters of AC filter banks and DC filter banks.

\begin{tabular}{|c|c|c|c|c|}
\hline \multirow[t]{2}{*}{ The Group } & \multirow{2}{*}{\multicolumn{2}{|c|}{ Parameter Description }} & \multicolumn{2}{|c|}{ Value } \\
\hline & & & Rectifier & Inverter \\
\hline \multirow{6}{*}{ The DC filter banks } & \multirow{3}{*}{ Capacitors (uF) } & $C_{1}$ & 1.6 & \\
\hline & & $C_{2}$ & 4.48 & \\
\hline & & $C_{3}$ & 5.81 & \\
\hline & \multirow{3}{*}{ Inductors (mH) } & $L_{1}$ & 10.869 & \\
\hline & & $L_{2}$ & 10.384 & \\
\hline & & $L_{3}$ & 20.6 & \\
\hline \multirow{5}{*}{ The AC filter banks (Type-A) } & \multirow{2}{*}{ Capacitors (uF) } & $C_{1 \mathrm{a}}$ & 1.605 & 1.963 \\
\hline & & $C_{2 \mathrm{a}}$ & 56.824 & 3.709 \\
\hline & \multirow{2}{*}{ Inductors (mH) } & $L_{1 \mathrm{a}}$ & 44.731 & 17.01 \\
\hline & & $L_{2 \mathrm{a}}$ & 1.239 & 9.918 \\
\hline & Resistors $(\Omega)$ & $R_{1 \mathrm{a}}$ & 2500 & 500 \\
\hline \multirow[t]{8}{*}{ The AC filter banks (Type-B) } & \multirow{3}{*}{ Capacitors (uF) } & $C_{1 \mathrm{~b}}$ & 1.578 & 1 \\
\hline & & $C_{2 \mathrm{~b}}$ & 7.218 & \\
\hline & & $C_{3 \mathrm{~b}}$ & 7.704 & \\
\hline & \multirow{3}{*}{ Inductors $(\mathrm{mH})$} & $L_{1 \mathrm{~b}}$ & 8.116 & \\
\hline & & $L_{2 \mathrm{~b}}$ & 129.39 & / \\
\hline & & $L_{3 \mathrm{~b}}$ & 1.634 & \\
\hline & \multirow{2}{*}{ Resistors $(\Omega)$} & $R_{1 \mathrm{~b}}$ & 400 & 1 \\
\hline & & $R_{2 \mathrm{~b}}$ & 1500 & 1 \\
\hline \multirow[t]{2}{*}{ The AC filter banks (Type-C) } & Capacitors (uF) & $C_{1 \mathrm{c}}$ & 1.616 & 1.972 \\
\hline & Inductors $(\mathrm{mH})$ & $L_{1 \mathrm{c}}$ & 2.721 & 3.964 \\
\hline
\end{tabular}

It should be noted that the project parameters of the AC filter banks given in table 2 are for the bipolar system, so they need to be converted.

\subsection{Model validation}

This section compares the time-domain responses between the small-signal model and the detailed simulation in PSCAD/EMTDC. The system operates at nominal operation state originally $\left(I_{\text {dcref }}=1.00\right.$ p.u., $U_{\text {dcref }}$ $=0.93$ p.u). Figure 6 and figure 7 show the dynamic response of the measured DC-current $I_{\mathrm{dcmr}}$ and DC-voltage $U_{\mathrm{dcmi}}$ when the system is subjected to different stepchanges.

The case in figure 6: $U_{\text {dcref }}$ changes from 0.93 p.u. to 0.90 p.u. at time $t=4 \mathrm{~s}$ and recovers to $0.93 \mathrm{p}$.u. at time $t=6 \mathrm{~s}$.

The case in figure $7: I_{\text {dcref }}$ changes from 1.00 p.u. to 0.95 p.u. at time $t=10 \mathrm{~s}$ and recovers to $1.00 \mathrm{p}$.u. at time $t=12 \mathrm{~s}$.

It can be seen that the responses from the small-signal model are consistent with the simulation results from PSCAD/EMTDC, which verifies the accuracy of the small-signal dynamic model effectively. 


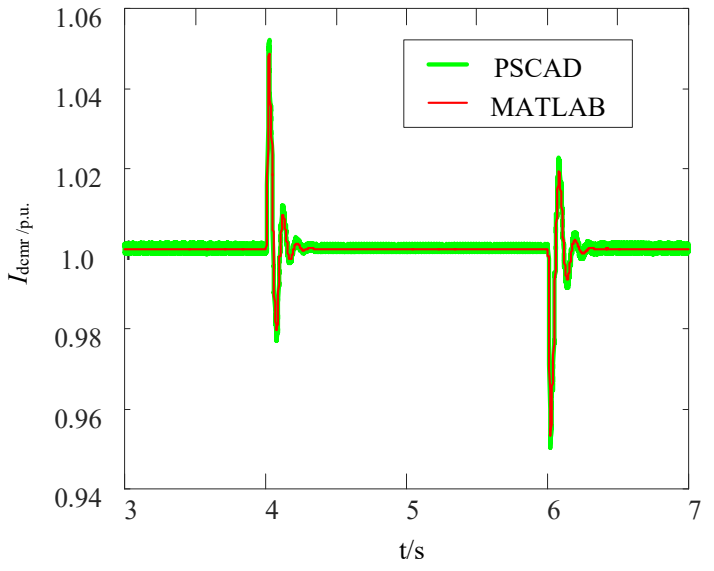

(a)

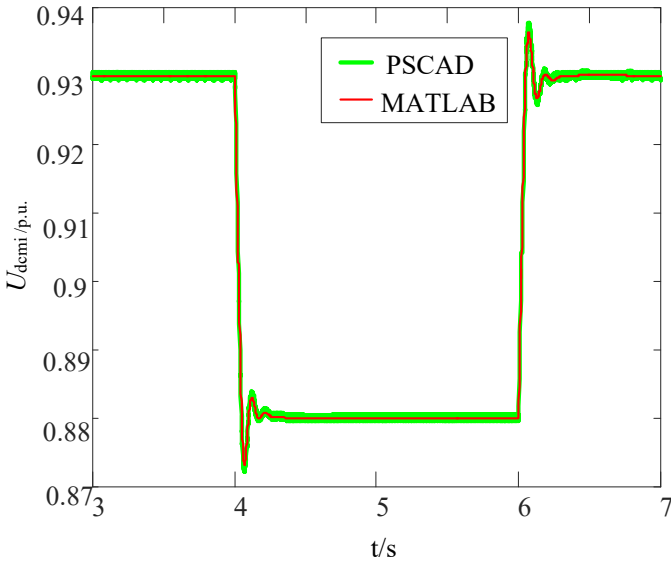

(b)

Figure 6. System dynamic responses under step-change of $U_{\text {dcref. }}$

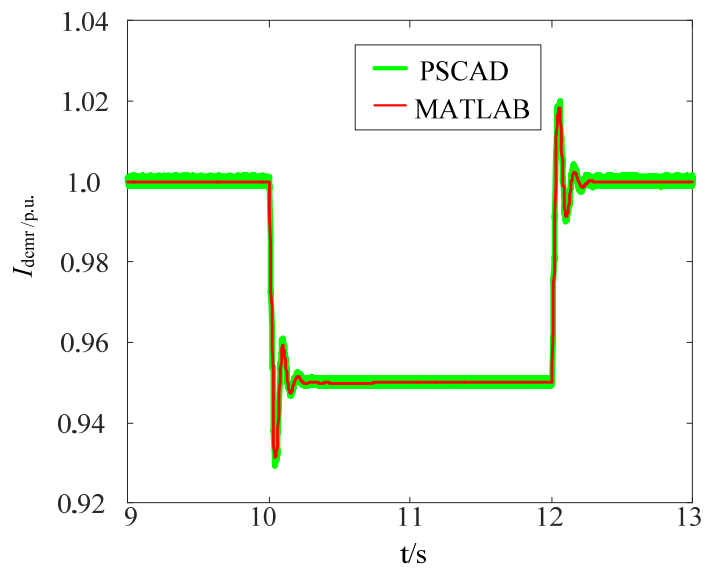

(a)

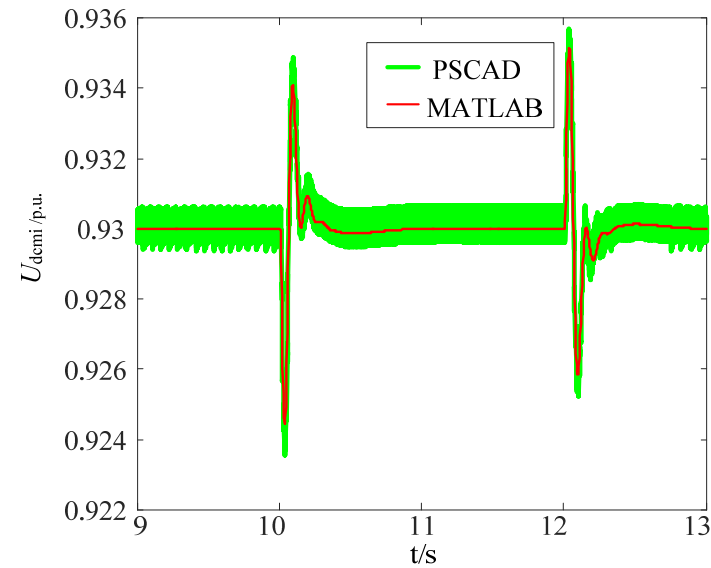

(b)

Figure 7. System dynamic responses under step-change of $I_{\text {dcref. }}$.

\section{Small-signal stability analysis}

For the inverter station, commutation failure is more likely to occur in the case of weak AC grid. Based on this, this section mainly studies the influence of the inverter controllers on the oscillation mode, damping characteristics, participation factor and feasible stable operation region of the LCC system.

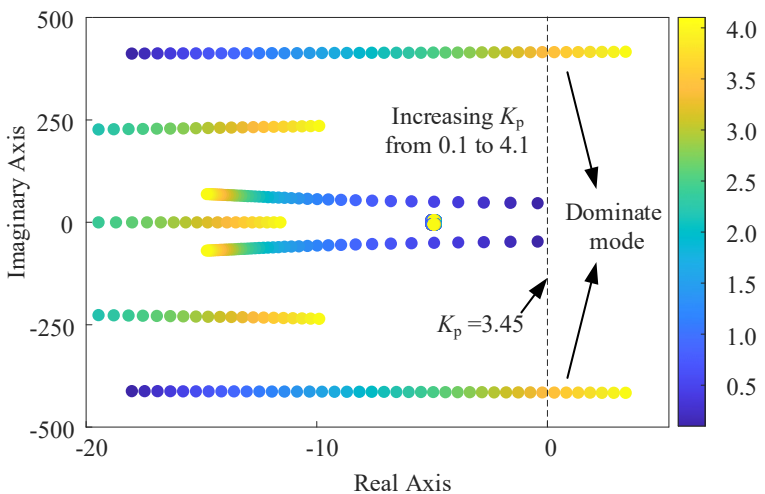

(a)

\subsection{Impact of Proportional Gain $\left(K_{p}\right)$ of Constant Voltage Controller}

Initially, the system is in a stable operation state (on the rectifier side: $\mathrm{SCR}=5, V_{\mathrm{pcc}_{\mathrm{r}}}=1.00 \mathrm{p} . \mathrm{u}, I_{\mathrm{dcref}}=1.00$ p.u.; on the inverter side: $\quad \mathrm{SCR}=2.5, \quad V_{\text {pcci }}=1.00$ p.u., $U_{\text {dcref }}=0.93$ p.u.). The control parameters are those of table 1 . When the proportional gain $K_{\mathrm{p}}$ of the constant voltage controller varies from 0.1 to 4.1 , the root loci of the eigenvalues are shown in figure 8 (a).

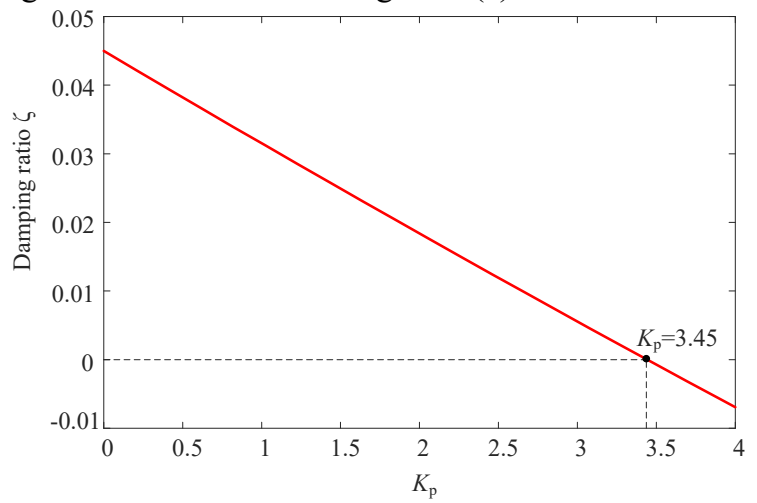

(b)

Figure 8. The eigen-analysis when $K_{\mathrm{p}}$ changes: (a) loci of the eigenvalues; (b) damping of dominant mode. 
Figure 8 (a) shows that all the eigenvalues are in the left half plane when $K_{\mathrm{p}}<3.45$, indicating that the system can keep stable. It also can be observed that the stability margin decreases gradually with the increase of $K_{\mathrm{p}}$. Figure 8 (b) depicts the damping ratio of the dominate mode when $K_{\mathrm{p}}$ changes. The result is that the damping of dominant mode decreases as $K_{\mathrm{p}}$ increases, and the small-signal stability is weakened correspondingly until the system becomes unstable at $K_{\mathrm{p}}=3.45$.
In order to verify the correctness of the above conclusions more intuitively, $K_{\mathrm{p}}$ is step-changed from 0.5 to 4.1 at time $t=4 \mathrm{~s}$ and other parameters are kept unchanged in the PSCAD/EMTDC. The simulation result of the $\mathrm{AC}$ rms voltage is given in figure 9. It can be seen that the system becomes unstable when $K_{\mathrm{p}}$ is 4.1 .

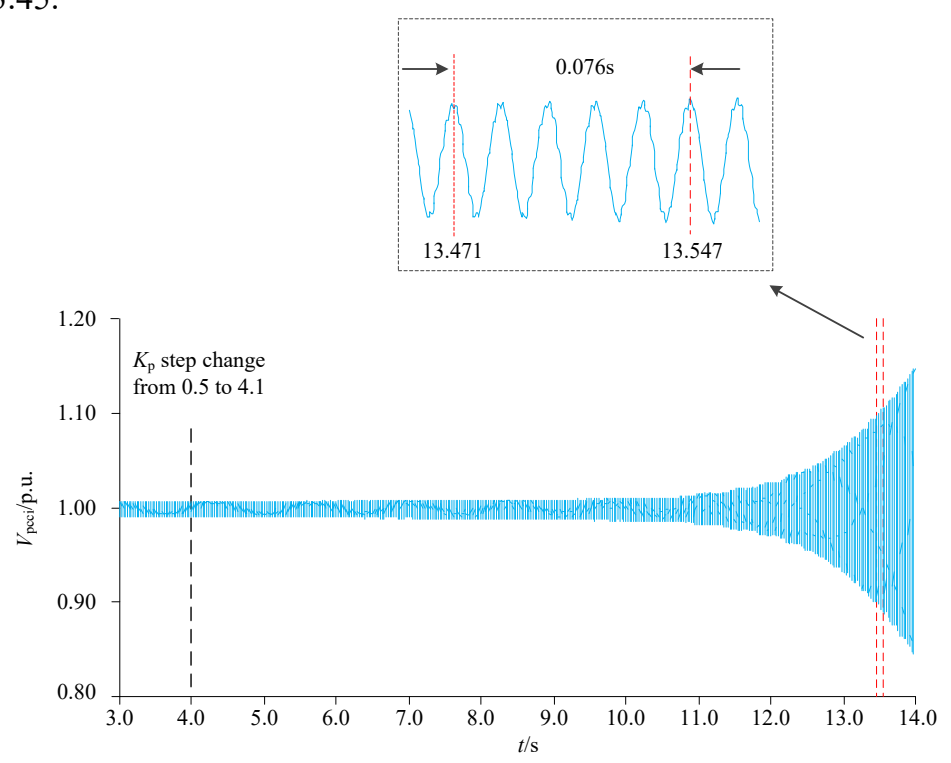

Figure 9. Dynamic response from PSCAD when $K_{\mathrm{p}}$ changes.

The oscillatory frequency of the dominant mode obtained from figure 9 is $65.79 \mathrm{~Hz}$. Based on the analysis of the small-signal model established in MATLAB, the eigenvalues of dominant mode corresponding to the parameters in figure 9 are $3.393+j 416.4$ and $3.393-j 416.4$, which shows corresponding oscillation frequency of the system is $66.27 \mathrm{~Hz}$. This result is in agreement with simulation result, so the eigen-analysis of figure 8 is accurate.

Furthermore, the participation factor is used to analyze the relative participation of each state variable in regard to the dominant mode. The comparison of the normalized participation factor when $K_{\mathrm{p}}=0.1$ and $K_{\mathrm{p}}=4.1$ is shown in figure 10 .

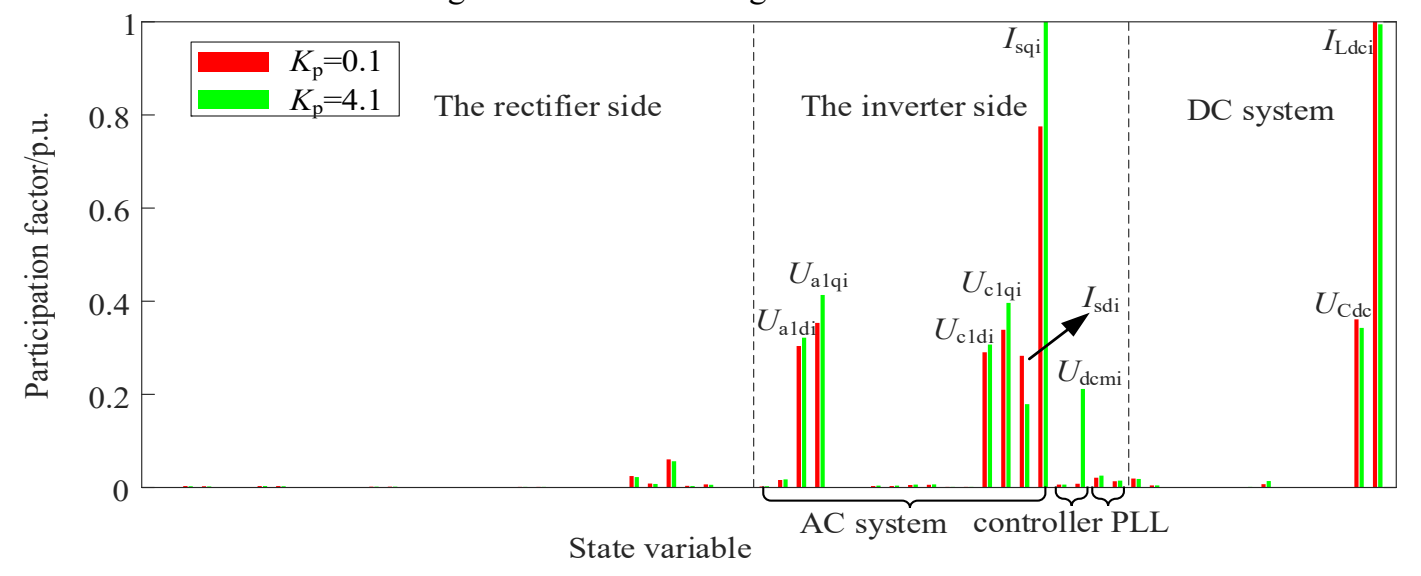

Figure 10. Participation factor of the state variables of dominant mode when $K_{\mathrm{p}}$ changes.

The participation factor of the state variable $U_{\mathrm{dcmi}}$ in the case of $K_{\mathrm{p}}=4.1$ is significantly higher than that in the case of $K_{\mathrm{p}}=0.1$, indicating that the main state variable making the system unstable is related to the constant voltage controller. Figure 10 also shows that the main state variables with relatively high participation factor remain unchanged as $K_{\mathrm{p}}$ changes greatly, that is to say, the impact of $K_{\mathrm{p}}$ on the dominant mode is not very prominent.
Moreover, the main state variables that affect the mode are relevant to the AC system on the inverter side and the DC line, which suggests indirectly that the dominant mode is not closely related to the parameters $K_{\mathrm{p}}$ of the control system.

In this section, the feasible region of $K_{\mathrm{p}}$ which can keep the small-signal dynamic model stable is further studied as a function of SCR. The maximum acceptable values of 
$K_{\mathrm{p}}$ are obtained when SCR varies from 2 to 3 . Figure 11 shows the acceptable maximum value curve, below which is the feasible region of $K_{\mathrm{p}}$. It can be found that the maximum allowable value of $K_{\mathrm{p}}$ decreases when the SCR increases under weak AC grid condition. In other words,

the feasible value of $K_{\mathrm{p}}$ at lower SCR is not necessarily suitable for higher SCR, which may be contrary to normal cognition. Thus, the possible variation range of SCR should be considered when selecting the proportional gain $K_{\mathrm{p}}$ of constant voltage controller.

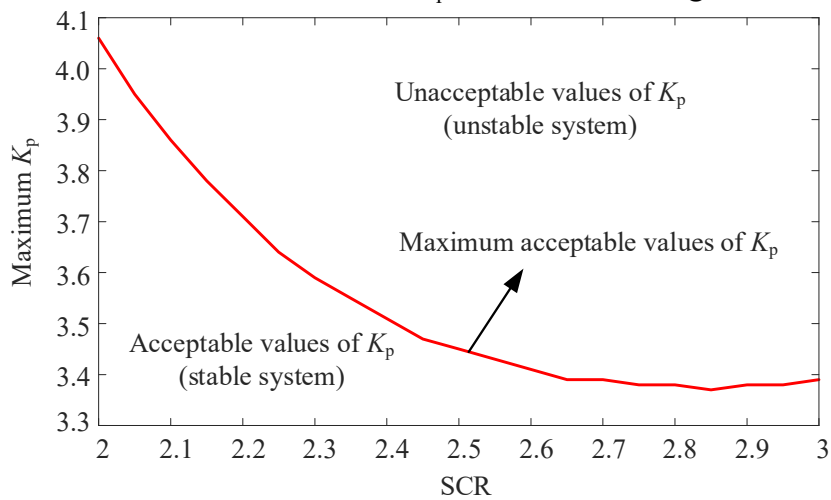

Figure 11. Acceptable values of $K_{\mathrm{p}}$ as a function of SCR

\subsection{Impact of integral gain $\left(\mathrm{K}_{\mathrm{i}}\right)$ of constant voltage controller}

Initially, the system operates at stable operating point (on

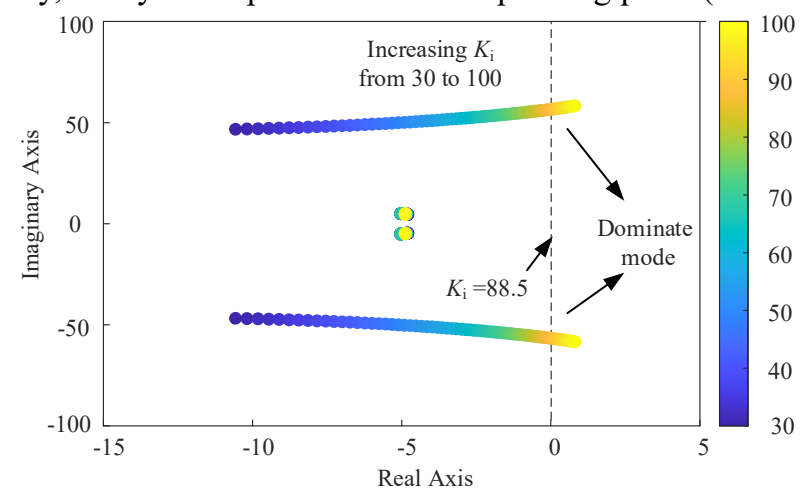

(a) the rectifier side: $\mathrm{SCR}=5, V_{\text {pcc_r }}=1.00$ p.u, $I_{\text {dcref }}=1.00$ p.u.; on the inverter side: $\mathrm{SCR}=2.5, \quad V_{\text {pcc }_{-} \text {i }}=1.00$ p.u. $U_{\text {dcref }}=0.93$ p.u.). Figure 12 (a) shows the eigenvalue loci of the system when the integral gain $K_{\mathrm{i}}$ of the constant voltage controller varies from 30 to 100 .

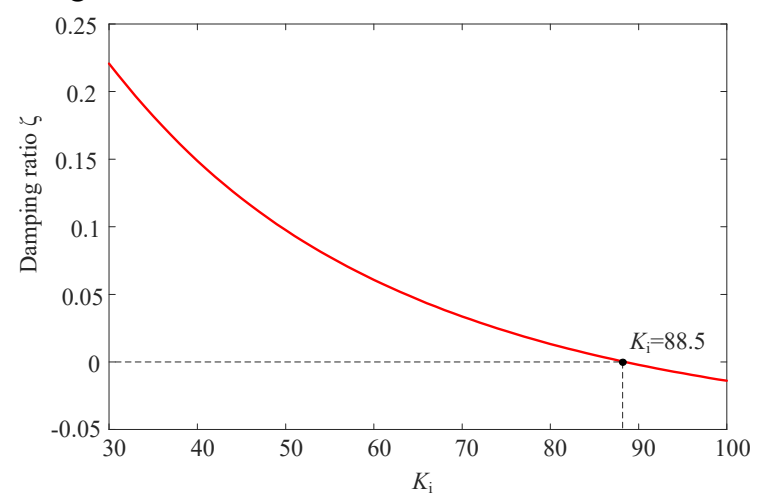

(b)

Figure 12. The eigen-analysis when $K_{\mathrm{i}}$ changes: (a) loci of the eigenvalues; (b) damping of dominant mode.

When $K_{\mathrm{i}}<88.5$, all the eigenvalues of system always remain in the left-half plane, which suggests that the system can operate stably. In addition, with the increase of $K_{\mathrm{i}}$, the stability margin of the system decreases and the small-signal stability is getting smaller. Curve of damping ratio of the dominant mode when $K_{\mathrm{i}}$ changes is shown in figure 12 (b). It is evident that the damping decreases with the increase of $K_{\mathrm{i}}$. Figure 13 shows the dynamic response of the study system from PSCAD/EMTDC as $K_{\mathrm{i}}$ is stepchanged from 30 to 100 at time $\mathrm{t}=4.0 \mathrm{~s}$. The observation from figure 13 indicates that the system can't keep stable when $K_{\mathrm{i}}=100$.

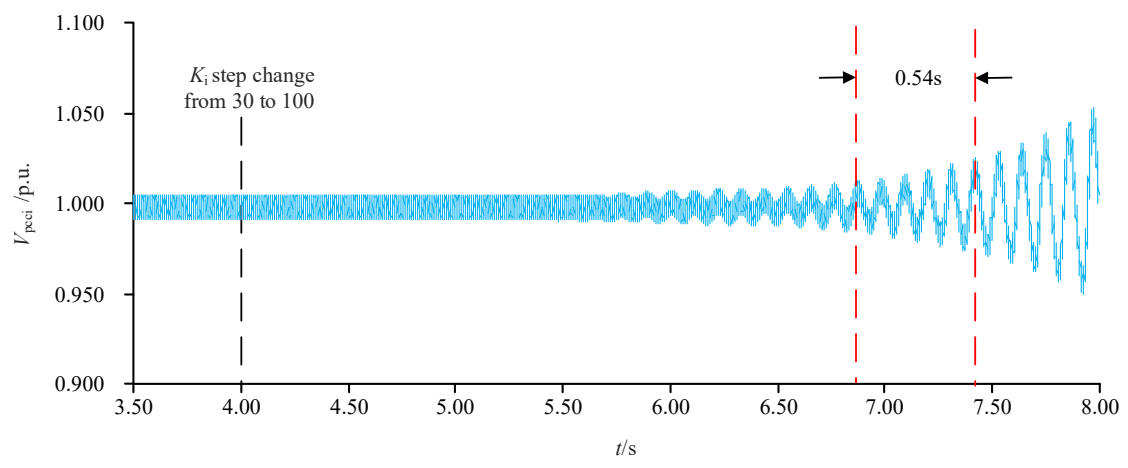

Figure 13. Dynamic response from PSCAD when $K_{\mathrm{i}}$ changes 
Furthermore, based on the established small-signal model, the eigenvalues corresponding to the dominant mode are $0.8113+j 58.30$ and $0.8113-j 58.30$ when $K_{\mathrm{i}}=100$, whose oscillation frequency is $9.28 \mathrm{~Hz}$. The actual oscillation frequency from the simulation result in PSCAD is $9.26 \mathrm{~Hz}$. The similar result verifies the correctness of the above eigen-analysis.

The comparison of the normalized participation factor when $K_{\mathrm{i}}=30$ and $K_{\mathrm{i}}=100$ is depicted in figure 14 . The participation factor of state variables $x_{1 \mathrm{i}}$ and $U_{\mathrm{dcmi}}$ become higher when $K_{\mathrm{i}}=100$ than that when $K_{\mathrm{i}}=30$, indicating the main state variables which lead to the instability of the system are related to the constant voltage controller. What's more, figure 14 shows that $x_{1 \mathrm{r}}$ is also the main state variable affecting the dominant mode, so the dominant mode is closely relevant to the rectifier constant current controller.

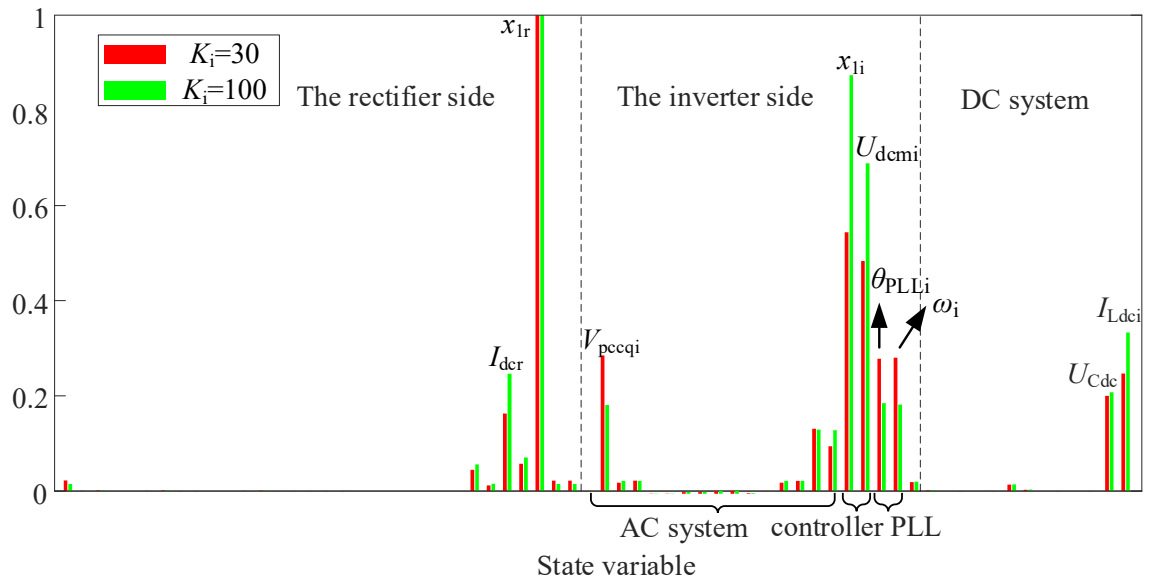

Figure 14. Participation factor of the state variables of dominant mode when $K_{\mathrm{i}}$ changes.

The impact of SCR on the inverter side, with the range of 2 to 3 , is further studied here. By calculating the acceptable maximum of $K_{\mathrm{i}}$ which can make the system keep stable at every SCR value, the maximum allowable value curve can be obtained as figure 15 . The feasible region of $K_{\mathrm{i}}$ is below the curve. It can be found that the critical value of $K_{\mathrm{i}}$ increases with the increase of SCR, in other words, increasing the SCR at the inverter station may improve the stability range of $K_{\mathrm{i}}$. However, excessive $K_{\mathrm{i}}$ value will still lead to the system instability.

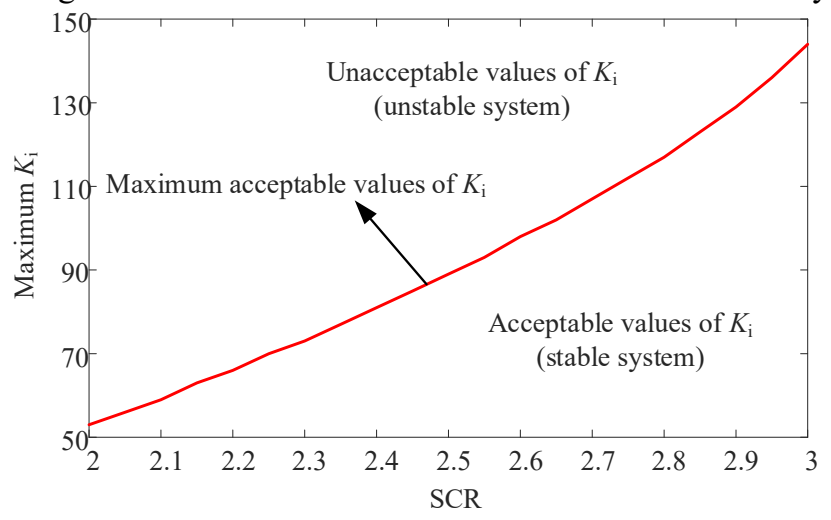

Figure 15. Acceptable values of $K_{\mathrm{i}}$ as a function of SCR.

\section{Conclusions}

This paper focuses on the influence of inverter controller parameters on the small-signal stability of LCC-HVDC system based on a practical project. By using the eigenanalysis method, the oscillation mode and damping characteristics of the LCC system can be obtained when controller parameters change. The corresponding conclusions are as follows:

1) Under weak AC grid condition $(2 \leq \mathrm{SCR} \leq 3)$, the small-signal stability of the system is weakened gradually with the increase of the proportional gain $K_{\mathrm{p}}$ of the constant voltage controller. At the same time, when SCR on the inverter side get larger, the maximum critical value of $K_{\mathrm{p}}$ becomes smaller. It should be noted that in order to ensure the stable operation of LCC-HVDC system, $K_{\mathrm{p}}$ need to be carefully selected according to the possible range of SCR.

2) As the integral gain $K_{\mathrm{i}}$ of the constant voltage controller increases, the small-signal stability of the system decreases gradually, and the maximum allowable value of $K_{\mathrm{i}}$ increases with the increase of SCR. 


\section{Acknowledgments}

This work was financially supported by China Southern Power Grid Science and Technology Projects (ZBKJXM20190056).

\section{References}

1. Zhao W. (2011) HVDC technology. China Electric Power Press, Beijing.

2. Nayak, O.B., Gole, A.M., Chapman, D.G. (1994) Dynamic performance of static and synchronous compensators at an HVDC inverter bus in a very weak AC system. IEEE Transactions on Power Systems. 9, 3: $1350-1358$.

3. Nayak, O.B., Gole, A.M., Chapman, D.G. (1995) Control sensitivity indices for stability analysis of HVDC systems. IEEE Transactions on Power Delivery. 10, 4: 2054-2060.

4. Jovcic, D., Pahalawaththa, N., Zavahir, M. (1999) Analytical modeling of HVDC-HVAC systems. IEEE Transactions on Power Delivery. 14, 2: 506-511.

5. Jovcic, D., Pahalawaththa, N., Zavahir, M. (1999) Small signal analysis of HVDC-HVAC interactions. IEEE Transactions on Power Delivery. 14, 2: 525-530.

6. Osauskas, C., Wood, A. (2003) Small-signal dynamic modeling of HVDC systems. IEEE Trans Power Del. 18, 1: 220-225.

7. Guo, C., Ning, L., Wang, H. (2017) Switchingfunction based dynamic model of LCC-HVDC station and small signal stability analysis. Power System Technology. 41, 12: 3862-3870.

8. Guo, C., Zhao, C., Iravani, R. (2017) Impact of phase-locked loop on small-signal dynamics of the line commutated converter-based high-voltage direct-current station. IET Generation, Transmission \& Distribution. 11, 5: 1311-1318.

9. Chen, W., Ye, Y., Wang J. (2020) Influence of Constant Voltage Control and Predictive Constant Extinction Angle Control on Small-signal Stability of HVDC. Automation of Electric Power Systems. 44, 18: 98-106.

10. Zheng, A., Guo, C., Cui, P., Jiang, W., Zhao, C. (2019) Comparative Study on Small-Signal Stability of LCC-HVDC System With Different Control Strategies at the Inverter Station. IEEE Access. 7: 34946-34953.

11. Szechtman, M., Wess, T., Thio, C.V. (1991) A benchmark model for HVDC system studies. In: Proc.Int.Conf.AC DC Power Transmiss. pp: 374-378. 